The conference will also attempt to bring into focus key issues and trends in the trade today through panel discussions among American and European antiquarian booksellers.

Newnham College, Cambridge, will serve as the conference headquarters site. Founded in 1871, Newnham College was originally designed by Basil Champreys in the "Queen Anne" style and built between 1875 and 1910. Later modern additions blend nicely with the original buildings, and the college is specially noted for its fine gardens. Two hundred single rooms have been reserved in
Newnham and in neighboring Selwyn College for conference attendees desiring to stay in college.

In addition, tours of libraries and museums in and around Cambridge are being planned, and the Provincial Book Fairs Association will hold a book fair at Newnham College during the conference.

Details about registration and accommodation will be available this coming April. For further information at that time, contact: Mary Ellen Davis, ACRL/ALA, 50 East Huron Street, Chicago, IL. 60611; (800) 545-2433; in Illinois (800) 545-2444; in Canada (800) 545-2455.

\title{
Moving fully-loaded stacks
}

\section{inexpensively}

\author{
By Stephen D. Fitt \\ Head, Special Resources Division \\ San Diego State University Library
}

\section{The Range Dolly solves stack-shifting problems}

\author{
at San Diego.
}

\begin{abstract}
A An expensive, labor-intensive activity in both academic and public libraries is the shifting of freestanding steel shelving to accommodate new floor layouts or the installation of new carpeting. All books must be removed from shelves and temporarily stored in boxes or on book trucks, with care taken to preserve some kind of call number order. During this period, patrons have limited or no access to the books. Shelving is at least partially disassembled and slid to the new location, in the case of new floor layouts, or out of the way, in the case of recarpeting. The shelving must then be reassembled and the books returned to the shelves in the correct call number order.

Devices and procedures which may help some-
\end{abstract}

what to simplify this procedure have been discussed in the literature; none have entirely solved the problem, due to requirements to unload ranges all or in part, or prohibitive prices. An article by Brian Alley discussed a dolly developed at Miami University. This device, using rolling trailer jacks, attaches to an upright column and permits movement of a range, after all the books have been removed from the shelves. ${ }^{1}$

In a 1986 article, James Segesta described several range-moving devices, and suggested procedures

${ }^{1}$ Brian Alley, "Moving Steel Stacks with a Special Dolly," Library Acquisitions: Practice and Theory 6 (1982): 253-57. 


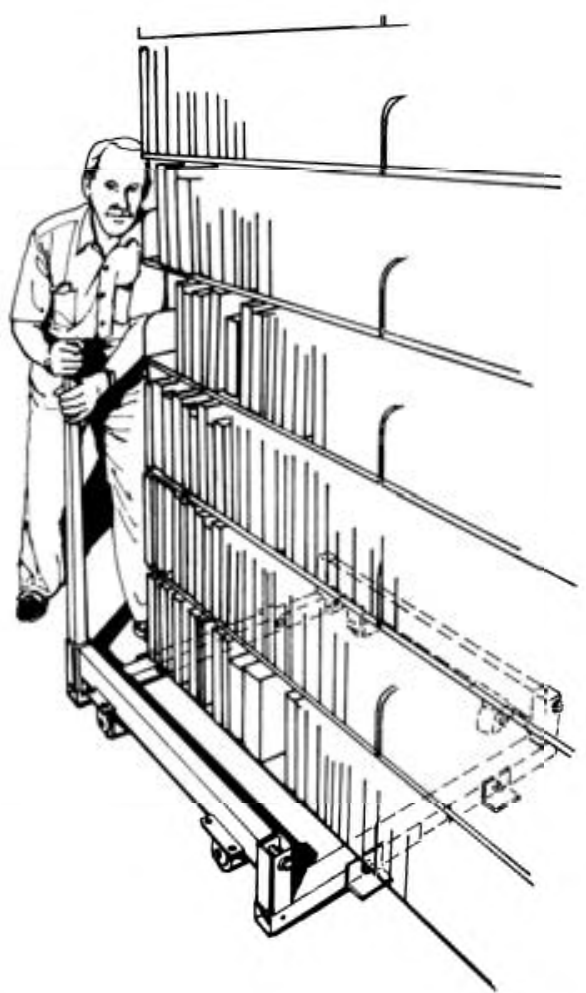

for moving ranges of shelving when recarpeting is necessary. A range-moving device developed at Cumberland College by Anthony Abriola consists of a steel frame on wheels and hoisting winches capable of lifting and moving fully-loaded ranges over plywood tracks. Another procedure involves sliding partially unloaded ranges over carpet. This is accomplished by tilting the ranges slightly and sliding a steel shelf under each upright, with the shelf acting as a runner. ${ }^{2}$

A more recent development at Moorhead State University called the "Range-Mover," consists of metal racks with large casters. Hydraulic jacks are used to lift each section from the top. The system is described as capable of moving fully-loaded ranges with little or no preparation of stacks. ${ }^{3}$

At San Diego State University, periodic moving of ranges has become the norm due to the gradual acquisition of space in a wing of the library which has been used for faculty offices and classrooms and because of recarpeting projects every five or six years. Major investments of time and student assistant monies, as well as limited patron access to significant portions of the collection accompany these moving projects-not to mention noise and general

${ }^{2}$ James Segesta, "Pulling the Rug out from under the Stacks," College and Research Libraries News, July/August 1986, 441-44.

Darrel M. Meinke, "Pulling the Rug out from under the Stacks (Revisited)," College and Research Libraries News, May 1988, 288-89. disruption of library services.

Enter Jim Duffy, a retired manufacturing engineer for General Dynamics Corporation in San Diego, who is serving as a volunteer assigned to the library administrative office. Jim became fully acquainted with the problems of shifting library shelving as he prepared and revised library floor plans and participated in overall space planning. As he studied the steel shelving and watched students tediously disassemble and reassemble ranges of shelving, he concluded there had to be an easier way.

The easier way is what Jim calls the Range Dolly-a device which permits the movement of a range of Contemporary Ames library shelving while books remain on the shelves. Each dolly supports the weight of one double-faced section, plus half the weight of each adjacent double-faced section of seven shelves loaded with books. As an example, one Range Dolly set of four dollies will support a range of seven double-faced sections, with one dolly under every other section.

Each Range Dolly consists of four pieces. Two identical cross pieces fit under the shelving adjacent to each upright column and two other identical pieces, with two swivel casters each, fit outside the shelving on opposite sides. The four pieces are attached using two bolts at each of the four corners. Each dolly has a post extending up chest-high so an individual can grasp it to either push or pull the dolly in the desired direction. Since each caster swivels, the range can be moved in any direction. The weight of the books and shelving is transferred down the upright columns to the midpoint of the base supports which rest on two angles attached to each of the Range Dolly cross pieces. The weight of the books, shelving and dollies is supported by casters, each of which is capable of supporting 750 pounds.

The free-standing section of shelving must be raised approximately $1 / 2$ inch to permit placing the Range Dolly cross pieces under it. This is accomplished by using a pry bar and placing $1 / 2$ inch wooden shims under the levelers on both sides of the range. The side pieces of the Range Dolly are then attached to the cross pieces. The free standing section is again raised slightly with a pry bar; the weight transferred to the dolly, shims removed and the levelers adjusted upward to clear the floor surface.

After each dolly is assembled in this manner, the loaded range (shelving and books) can be moved easily by having a person at each dolly pull or push the post to move the range to its desired location. Once in the new location, the above procedure is reversed and the dolly is disassembled and removed from under the range.

A crew of four who have performed the operation several times can move a loaded seven-section range of steel shelving in 15 minutes or one personhour. Carpets present no problem for the Range Dolly, other than the fact that it is a little more dif- 
ficult to overcome inertia. Most carpeting used in libraries is commercial grade with a very tight weave and low nap. The Range Dolly casters are designed to support and move heavy office equipment on carpeting or hard surfaces.

A standard set of Range Dollys disassembles into easily stored components and require minimal tools for use. The prototype Range Dolly used at San Diego State University was operated using only a sacket wrench, a two-foot long pry bar, and some half-inch shims. While the current Range Dolly was designed for use with Contemporary Ames steel shelving, Jim Duffy is in the process of engineering adaptations which would allow its use on other types of steel library shelving. Because the concept is quite simple, requiring no winches or jacking devices, the Range Dolly can be manufactured and purchased at relatively modest cost. It should pay for itself the first time reorganization of shelving arrangements or recarpeting is required. A major advantage of the Range Dolly is that the weight of the shelving and books is borne in exactly the same manner in which the shelving was originally manufactured-from the feet through the uprights. No unusual stress is applied to any portion of a range during the assembly of the Range Dolly or during the movement of a range.

Based on the number of articles which have ap- peared proposing solutions to the need to move fully-loaded ranges, manufacturers of library shelving should recognize the need libraries have to occasionally move library shelving and the advantages to libraries of being able to move fully-loaded ranges, and design shelving to permit such movement. That this would make their shelving more attractive to libraries is obvious. Even shelving which is designed to be "permanently" attached to the floor for seismic safety purposes should have the capability of being moved expeditiously. Libraries requiring new library shelving could encourage this process by writing into their procurement specifications the requirement that shelving be designed to permit movement of a fully-loaded range.

A long-term problem was resolved at San Diego State University by Jim Duffy through the development of the Range Dolly. A major reorganization of the 5th level of the library will be reduced to a minor inconvenience for both library users and staff. Even at the height of the shift, virtually all materials will be readily accessible.

Again, creative problem solving, in the person of Jim Duffy, found a need and developed a solution. Further information on this Range Dolly may be obtained from Jim by writing to him at 9300 Dillon Drive, La Mesa, CA 92041.
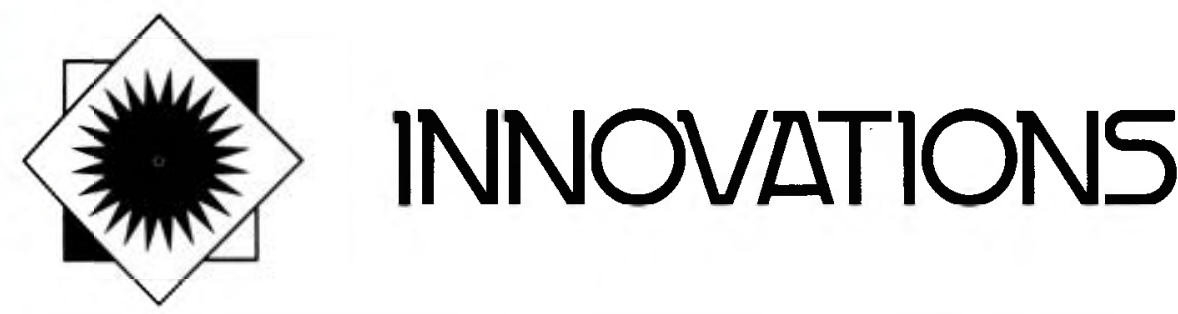

\section{Humor and creativity: Staff newsletters}

\section{by Norman D. Stevens \\ Director \\ The Molesworth Institute}

Some unperceptive soul has alleged that "There is nothing duller than a [staff] newsletter from another library. It is full of arcane references to people we don't know and don't care about." $A$ more intelligent observer has suggested that "If anyone ever deigns to write a comprehensive history of li-

\footnotetext{
${ }^{\mathrm{I}}$ Norman D. Stevens, "Contemporary American Minor Library Publications," Library Science Annual 2 (1988): 51.
}

brary humor...library [staff] newsletters will constitute a primary source of enormous value.",

Library staff newsletters, as they exist in so many contemporary American academic libraries, are unusual publications. As a substantial element of a large class of contemporary American minor library publications they constitute the most neglected element of our professional literature. They

\footnotetext{
${ }^{2}$ Ibid., 52.
} 